\title{
TỔ CHỨC KẾ TOÁN TRÁCH NHIỆM TRONG DOANH NGHIỆP NHỎ VÀ VÙ̀A
}

\section{Organization of responsibility acounting in small and medium sized enterprise}

Ngày 20/10/2016; ngày phản biện: 22/2/2017; ngày duyệt đăng: 22/3/2017

Nguyễn Thị Kim Ngân*

\section{TÓM TÁ́T}

Kế toán trách nhiệm là một nội dung cơ bản của kế toán quản trị, là quá trình thu thập và báo cáo các thông tin tài chính và phi tài chính của đơn vị, thực chất kế toán trách nhiệm chính là quá trình phân định, thiết lập những quyền hạn, trách nhiệm cho mỗi bộ phận, cá nhân và một hệ thống chỉ tiêu, công cụ báo cáo kết quả của mỗi bộ phận. Hiện nay, các doanh nghiệp nhỏ và vừa chưa thực sự quan tâm tới việc sử dụng công cụ kế toán trách nhiệm nhằm phục vụ cho việc kiểm soát và đánh giá kết quả hoạt động của các bộ phận. Do đó, bài viết tập trung phân tích việc sử dụng công cụ kế toán trách nhiệm trong doanh nghiệp nhỏ và vừa, từ đó có những đề xuất để tổ chức công cụ này trong các doanh nghiệp nhỏ và vừa một cách hiệu quả.

Từ khóa: Doanh nghiệp nhỏ và vùa; kế toán trách nhiệm; trung tâm trách nhiệm; trung tâm chi phí; trung tâm doanh thu; trung tâm lợi nhuận; trung tâm đầu tu.

\begin{abstract}
Reponsibility accounting is a basic component of management accounting. It is the process of collecting and reporting enterprises' financial and non-financial information. Essentially responsibility accounting is the process of delimitation, establishing powers and responsibilities for each department or individual, a system of indicators, and results reporting tools for each division. Currently, small and medium-sized enterprises are not really interested in using reponsibility accounting tools to help in controlling and evaluating the results of operations of departments. Therefore, this article focuses on analyzing the use of responsibility accounting for small and medium-sized enterprises which have proposed to use this tool effectively in thier enterprises.
\end{abstract}

Keywords: Small and medium sized enterprise; reponsibility accounting; responsibility center; cost center; revenue center; profit center; investment center.

\section{Mở đầu}

Kế toán trách nhiệm là một nội dung cơ bản của kế toán quản trị, là quá trình thu thập và báo cáo các thông tin tài chính và phi tài chính của đơn vị, hệ thống này thù̃a nhận mối cá nhân, bộ phận trong một tổ chức có quyền chi đạo và chịu trách nhiệm về nhũng nghiệp vu riêng biệt thuộc phạm vi quản lý của mình [4]. Nói cách khác, kế toán trách nhiệm "cá nhân hóa" các thông tin kế toán thông qua trách nhiệm cá nhân về các chỉ tiêu doanh thu, chi phí, lợi nhuận hay đầu tư.

Trong quan niệm thông thường, kế toán quản trị nói chung và kế toán trách nhiệm nói riêng được coi là cần thiết và phù hợp cho các doanh nghiệp có quy mô lớn. Với các doanh nghiệp nhỏ và vừa, hoạt động thường không quá phức tạp và không tạo ảnh hưởng lớn đến xu hướng thị trường cũng như các đối thủ cạnh tranh khác, chính vì vậy bản thân các doanh nghiệp nhỏ và vừa cùng các đối tác có liên quan đều chưa thực sự quan tâm tới việc sử

*Đại học Tân Trào 
dụng công cụ kế toán trách nhiệm. Nhằm phục vụ cho việc kiểm soát và đánh giá kết quả hoạt động của các bộ phận, kế toán quản trị đã sử dụng phương pháp thích ứng - đó là hệ thống kế toán theo các trung tâm trách nhiệm hay còn gọi là kế toán trách nhiệm. Thông qua hệ thống đo lường, báo cáo đánh giá các hoạt động từ công cụ kế toán trách nhiệm, các nhà quản trị sẽ bao quát được tình hình kinh doanh của đơn vị, theo dõi các quyền và trách nhiệm của người điều hành quản lý ở cấp thấp hơn để đưa ra những quyết định hiệu quả, chính xác và đúng đắn.

Bài viết tập trung phân tích việc sử dụng công cụ kế toán trách nhiệm của doanh nghiệp nhỏ và vừa, từ đó có những đề xuất để tổ chức công cụ này nhằm kiểm soát và đánh giá hiệu quả hoạt động trong các doanh nghiệp này hiện nay.

Phương pháp nghiên cứu chủ yếu của bài viết là: điều tra, tổng hợp, phân tích.

\section{Nội dung}

\subsection{Vai trò của kế toán trách nhiệm} trong doanh nghiệp

Hệ thống kế toán trách nhiệm được thiết lập nhằm thúc đẩy muc tiêu giũa các nhà quản trị trong các tổ chức phân quyền [3, tr208], đồng thời nó cũng cung cấp thông tin cho các nhà quản trị để họ điều hành và quản lý bộ phận mình phụ trách một cách hiệu quả. Nói cách khác, kế toán quản trị là một công cụ để đo lường về kết quả hoạt động của một khu vực nào đó trong tổ chức, qua đó giúp nhà quản trị kiểm soát và đánh giá trách nhiệm quản trị ở từng cấp quản trị khác nhau.

Vai trò của kế toán trách nhiệm được thể hiện ở những nội dung sau:

- Kế toán trách nhiệm giúp xác định sụ đóng góp của tùng đonn vị, bộ phận [4] vào lợi ích của toàn bộ doanh nghiệp;
- Kế toán trách nhiệm cung cấp $c \sigma^{\circ} s o^{\circ}$ cho việc đánh giá chất luợng về kết quả hoạt động của nhũng nhà quản lý bộ phận [4];

- Kế toán trách nhiệm đo lường kết quả hoụt động của các nhà quản lý [4];

- Kế toán trách nhiệm thúc đẩy các nhà quản lý bộ phận điều hành bộ phận của mình theo phương cách phù hơp vói nhũng muc tiêu co bản [4] của toàn bộ doanh nghiệp.

Thông qua vai trò của kế toán trách nhiệm trong doanh nghiệp nhỏ và vừa có thể khẳng định để hòa nhập vào sự phát triển chung của nền kinh tế đòi hỏi sự phát triển của các doanh nghiệp, các đơn vị kinh doanh. Kế toán trách nhiệm với việc thực hiện chức năng tư vấn sẽ là cần thiết để các doanh nghiệp nhỏ và vừa có thể phát triển ổn định hiện tại và tương lai.

\subsection{Kế toán trách nhiệm trong các doanh nghiệp nhỏ và vừa}

Bộ máy kế toán của các doanh nghiệp nhỏ và vừa được xây dựng chủ yếu tập trung vào công tác thu nhận, xử lý và cung cấp thông tin của kế toán tài chính cho việc tổng hợp mà chưa có bộ phận riêng phục vụ cho yêu cầu quản trị cũng như phân tích hoạt động kinh doanh. Các doanh nghiệp cũng chỉ quan tâm tới việc tổ chức cơ cấu bộ máy sao cho phù hợp với quy mô và loại hình hoạt động sản xuất kinh doanh.

Tuy nhiên, việc quản lý và sử dụng vốn; quản lý và sử dụng tài sản; quản lý doanh thu, chi phí và kết quả hoạt động sản xuất kinh doanh được các doanh nghiệp phân cấp quản lý rõ ràng theo quy chế quản lý tài chính do chính doanh nghiệp ban hành. Các đơn vị trực thuộc được giao quyền sử dụng vốn và tài sản, còn doanh nghiệp là chủ sở hữu các tài sản đó. Các đơn vị trực thuộc tổ chức sản xuất kinh doanh quản lý mọi vật tư, tài sản thiết bị của đơn vị được giao, chịu trách nhiệm quản lý và 
hạch toán các chi phí, thực hiện tốt việc thanh quyết toán hàng tháng, giải quyết thu hồi công nợ kịp thời. Các đơn vị chủ động trong việc bố trí, sắp xếp lực lượng lao động do doanh nghiệp giao quản lý trong đơn vị phù hợp với trình độ chuyên môn nghiệp vụ, khả năng lao động của từng người và phù hợp với yêu cầu sản xuất kinh doanh của đơn vị. Ngoài ra, rất nhiều các doanh nghiệp đã áp dụng phương thức giao khoán, hình thức này đã có nhiều đổi mới sao cho phù hợp với điều kiện một tỉnh miền núi, năng lực của đơn vị nhận khoán, quy định rõ trách nhiệm, nghĩa vụ, quyền hạn của đơn vị giao khoán và đơn vị nhận khoán trong các hoạt động.

Việc xây dựng kế hoạch, lập các dự toán được diễn ra theo định kỳ. Việc phân chia quyền kiểm soát doanh thu, chi phí được xác định. Công tác kế toán có sự vận dụng hài hoà giữa kế toán tài chính và kế toán quản trị. Tuy nhiên, các doanh nghiệp chưa có hệ thống kế toán trách nhiệm hoàn hảo nên các trung tâm trách nhiệm chưa thực sự tồn tại theo đúng nghĩa của nó. Hệ thống báo cáo kế toán quản trị của doanh nghiệp chưa được toàn diện, các báo cáo hiện tại chưa cung cấp đầy đủ các thông tin phục vụ đánh giá trách nhiệm và mức độ hoàn thành nhiệm vụ của các cấp quản lý và cá nhân, chưa đủ để phản ánh hiệu quả sử dụng vốn, chưa giúp cho nhà quản lý các bộ phận điều hành và kiểm soát các hoạt động sản xuất kinh doanh cũng như đánh giá thành quả của các đơn vị, bộ phận. Bên cạnh đó các báo cáo vẫn chưa thể hiện rõ luồng di chuyển thông tin và trách nhiệm của nhà quản lý tương ứng với luồng thông tin đó.

Trên cơ sở đó, việc vận dụng và xây dựng công cụ kế toán trách nhiệm trở thành cần thiết đối với các doanh nghiệp nhỏ và vừa giúp phát huy tối đa các nguồn lực, tận dụng các lợi thế nhằm tăng cường năng lực cạnh tranh cũng như nâng cao hiệu quả sản xuất kinh doanh.

\subsection{Tổ chức hệ thống kế toán trách} nhiệm trong doanh nghiệp nhỏ và vừa

2.3.1. Xác định các trung tâm trách nhiệm và phân quyền quản lý theo trách nhiệm

Trung tâm trách nhiệm là một bộ phận trong tổ chức, nơi mà nhà quản trị bộ phận chịu trách nhiệm về kết quả hoạt động của bộ phận mình. Theo đó, căn cứ vào cơ cấu tổ chức và mức độ phân cấp quản lý của doanh nghiệp mà có hệ thống các trung tâm trách nhiệm tương ứng. Trung tâm trách nhiệm được hình thành tù đặc điểm tổ chức bộ máy hoạt động của tùng doanh nghiẹp và nó phu thuộc vào đặc điểm của hoạt động kinh doanh theo tìng ngành nghề cu thể [3, tr 179].

Trung tâm trách nhiệm phát huy tác dụng khi cơ chế quản lý tài chính được phân cấp cụ thể cho từng người, từng bộ phận gắn với trách nhiệm, nghĩa vụ và quyền lợi trong từng hoạt động cụ thể. Dựa trên sự phân cấp quản lý theo cơ cấu tổ chức hiện nay tại các doanh nghiệp nhỏ và vừa, có thể tổ chức thành các trung tâm trách nhiệm, bao gồm: trung tâm chi phí, trung tâm doanh thu, trung tâm lợi nhuận và trung tâm đầu tư. Mô hình trung tâm trách nhiệm được tổ chức như sau:

So đồ 2.1. Mô hình trung tâm trách nhiệm

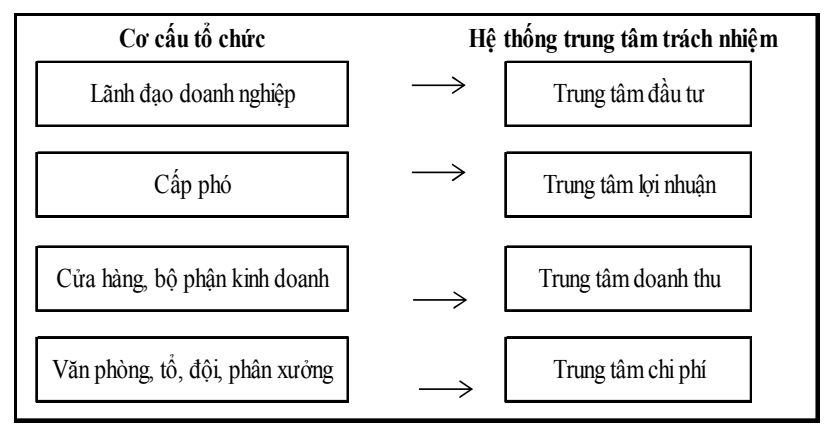

Việc phân chia các trung tâm trách nhiệm sẽ tạo ý tuoơng cho lãnh đạo doanh nghiệp trong việc thiết lạp một mô hình co cấu tốt nhất, phân chia trách nhiệm quản lý lập kế hoạch, phân tích, báo cáo, tách bạch theo 
nhóm hoạt động nhằm phát huy tối đa nguồn lục và thuận tiện cho quản lý [2, tr 205].

So đồ 2.2. Mô hình phân quyền quản lý theo trách nhiệm

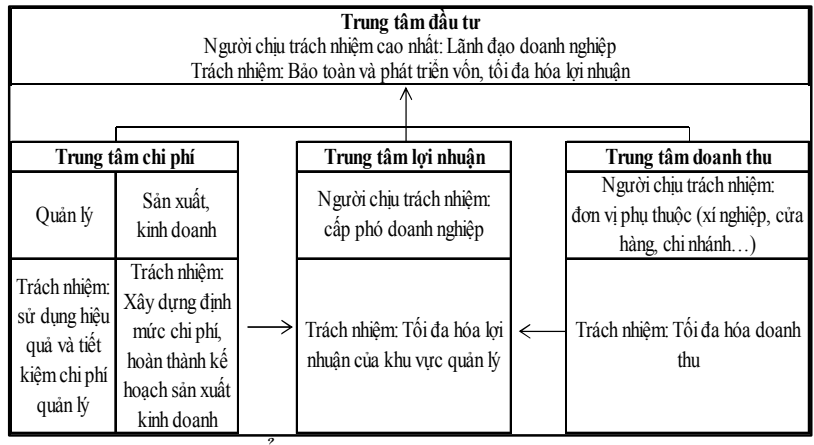

2.3.2. Tổ chức lập dự toán tại các trung tâm trách nhiệm

Các dự toán được lập cần xây dựng chi tiết phù hợp với nhu cầu sử dụng và kiểm soát thông tin. Mẫu biểu dự toán cần được thiết kế theo hướng phục vụ công tác quản trị tại doanh nghiệp.

Các dự toán tại trung tâm chi phí nên được sắp xếp theo cách ứng xử, và xây dựng theo hướng linh hoạt. Theo đó các chi phí được sắp xếp theo cách ứng xử của hoạt động và được chia thành ba dạng cơ bản đó là biến phí, định phí và chi phí hỗn hợp. Điều này giúp cho việc xây dựng báo cáo kết quả kinh doanh theo các bộ phận nhằm phân tích và đánh giá hiệu quả của từng bộ phận để đưa ra quyết định chính xác phù hợp với quy mô doanh nghiệp. Đồng thời, kế toán trách nhiệm chi phí xây dựng dự toán theo hướng linh hoạt có thể xác định chi phí dự kiến cho mức độ hoạt động thực tế nên sẽ rất có ích trong việc so sánh với chi phí thực tế phát sinh. Dự toán linh hoạt được lập cho bất kỳ một mức độ hoạt động nào trên cơ sở phân tách giữa biến phí và định phí.

Hiện nay, dự toán doanh thu tiêu tại hầu hết các doanh nghiệp vừa và nhỏ mới chỉ thiên về các chỉ tiêu tổng hợp của kế toán tài chính. Do đó, tại trung tâm doanh thu, dự toán này nên được xây dựng chi tiết đến từng loại sản phẩm. Để chi tiết theo sản phẩm, kế toán trách nhiệm doanh thu cần phải xuất phát từ tình hình tiêu thụ sản phẩm thực tế kỳ trước, sau đó điều chỉnh theo các xu hướng biến động hiện tại.

Tại trung tâm lợi nhuận, cần xây dựng dự toán phù hợp với trung tâm chi phí bằng hình thức lập theo số dư đảm phí. Cách tiếp cận số dư đảm phí rất có ích cho các nhà quản trị dễ báo cáo nội bộ vì nó nhấn mạnh đến sự ứng xử của chi phí. Theo cách tiếp cận này, chi phí được phân loại theo mối quan hệ với khối lượng hoạt động (sự ứng xử) khi lập báo cáo dự toán:

Doanh thu .XXX

Trừ: Biến phí . $\mathrm{XXX}$

Số dư đảm phí XXX

Trừ: Định Phí ..XXX

Lợi nhuận thuần . $\mathrm{XXX}$

Dự toán tại trung tâm đầu tư cũng cần được lập một cách tổng quát, nhằm tạo cơ sở cho việc kiểm soát và đối chiếu với thực tế nhằm đánh giá trách nhiệm của nhà quản lý cấp cao. Dự toán cần thể hiện các thông tin cơ bản đó là: doanh thu thuần, lợi nhuận trước và sau thuế, vốn đầu tư, tỷ lệ hoàn vốn đầu tư, tỷ lệ hoàn vốn mong muốn.

\subsubsection{Xây dưng bộ máy kế toán để hoàn} thiện việc xư lý thông tin trong các trung tâm trách nhiệm

Các doanh nghiệp nhỏ và vừa nên sử dụng mô hình kết hợp giữa kế toán tài chính và kế toán quản trị. Theo mô hình này, kế toán doanh nghiệp đồng thời đảm nhiệm hai nhiệm vụ: thu nhận, xử lý thông tin kế toán và kế toán quản trị. Sự phù hợp của mô hình này thể hiện như sau :

- Mô hình này cho phép kế thừa những nội dung của kế toán quản trị đã tồn tại;

- Kế toán quản trị được xây dựng và phát triển ở mức độ thấp, chưa đủ điều kiện để tách riêng thành một bộ phận độc lập và chuyên sâu; 
- Tiết kiệm chi phí kế toán, đảm bảo nguyên tắc tiết kiệm và hiệu quả;

- Phù hợp với trình độ quản lý, năng lực cán bộ công nhân viên.

Tuy nhiên, khi vận dụng mô hình này thì vai trò của kế toán quản trị thường bị lu mờ do nhà quản lý các doanh nhiệp nhỏ và vừa chưa thấy được tầm quan trọng của thông tin trong kế toán quản trị. Chính vì vậy, cần phải phân công trách nhiệm cụ thể đối với cán bộ kế toán làm nhiệm vụ kế toán tài chính hay kế toán quản trị. Đảm bảo thông tin thu thập cho mục tiêu quản trị phải được ghi chép, cập nhật thường xuyên, thích hợp và thống nhất giữa các kỳ.

\subsubsection{Tổ chức lại hệ thống báo cáo kế} toán trách nhiệm

Một trong những khâu quan trọng trong quá trình sử dụng công cụ kế toán trách nhiệm tại công ty là việc đánh giá trách nhiệm của từng bộ phận đối với việc thực hiện mục tiêu chung toàn công ty thông qua các báo cáo kế toán trách nhiệm. Các báo cáo thực tế được tạo lập cần có sự phân tích và đánh giá trách nhiệm cũng như thành quả của từng cấp quản lý. Qua đó nâng cao được trách nhiệm cũng như năng lực quản lý và hiệu quả kinh doanh của công ty. Các báo cáo kế toán trách nhiệm phải thể hiện được trách nhiệm của từng cấp quản lý, từng trung tâm trách nhiệm, từ trung tâm chi phí đến trung tâm đầu tư.

Đối với trung tâm chi phí, cần lập "Báo cáo tình hình thực hiện chi phí, giá thành sản phẩm", báo cáo trên được lập cho từng tháng, từng phần việc hoặc từng sản phẩm, dự kiến thời gian chuẩn bị phục vụ cho công tác sản xuất kinh doanh. Sau khi kiểm tra tính chính xác và phù hợp, báo cáo này sẽ cung cấp thông tin cho nhà quản lý biết được tiến độ cấp vật tư, tiền vốn, nhân lực cho từng tháng, từng phần việc hoặc từng sản phẩm và cho cả quá trình sản xuất kinh doanh.

Đối với trung tâm doanh thu, cần lập "Báo cáo tình hình thực hiện doanh thu theo yêu cầu quản trị’", kế toán trách nhiệm sẽ xây dựng báo cáo về tình hình thực hiện dự toán tiêu thụ cho từng sản phẩm, công việc, lao vụ. Trong đó thể hiện doanh thu thực tế so với dự toán và phân tích chênh lệch giữa chúng do các nhân tố sản lượng bán, giá bán cho từng loại sản phẩm, lao vụ, dịch vụ, qua đó kết luận cụ thể về hiệu quả của trung tâm cũng như trách nhiệm của nhà quản trị trung tâm.

Đối với trung tâm lợi nhuận, cần lập "Báo cáo kết quả kinh doanh theo doanh theo số dư đảm phí, báo cáo bộ phận". Báo cáo trách nhiệm trung tâm lợi nhuận được xây dựng theo hình thức số dư đảm phí sẽ rất hữu ích để đánh giá trách nhiệm quản lý và đóng góp thành quả của từng trung tâm lợi nhuận. Để đánh giá trách nhiệm quản lý và thành quả hoạt động cần tiến hành so sánh giữa lợi nhuận đạt được với dự toán, đồng thời kết hợp với kết quả phân tích của các trung tâm doanh thu, chi phí từ đó thấy được mức độ ảnh hưởng của các nhân tố doanh thu, chi phí đến lợi nhuận.

Đối với trung tâm đầu tư, cần lập "Báo cáo kêt quả kinh doanh theo doanh theo số dư đảm phí, báo cáo bộ phận, chỉ tiêu ROI và RI", báo cáo được lập tại cấp cao nhất. Báo cáo được lập làm cơ sở cho việc đánh giá hiệu quả hoạt động của các bộ phận và hiệu quả của từng lĩnh vực hoạt động mà doanh nghiệp đã đầu tư. Để đánh giá trách nhiệm quản lý và thành quả của trung tâm đầu tư, ta dựa trên tỷ lệ hoàn vốn đầu tư ROI, lợi nhuận còn lại RI, ngoài ra ta so sánh các chỉ tiêu trên bảng báo cáo kết quả đầu tư giữa thực tế so với dự toán cả về giá trị và tỷ lệ để đánh giá việc tăng giảm thông qua các độ lệch. 
Trình tụ báo cáo thông tin trong hệ thống kế toán trách nhiệm bắt đà̀u tù cấp quản trị thấp nhất cho đến cấp quản trị cao nhất [1,tr189]. Mức độ chi tiết của báo cáo giảm dần theo sự gia tăng của các cấp quản lý trong doanh nghiệp. Mỗi nhà quản trị trong doanh nghiệp nhận được báo cáo thực hiện của chính bộ phận mình và báo cáo thực hiện của các bộ phận dưới quyền.

\subsubsection{Xây dưng hệ thống chỉ tiêu đánh giá} trung tâm trách nhiệm

\section{a. Trung tâm chi phí}

Chỉ tiêu đánh giá hiệu quả của trung tâm chi phí là chênh lệch giữa các khoản mục chi phí thực tế so với chi phí dự toán đã được lập theo định mức thiết kế. Định kỳ, chỉ huy trưởng các bộ phận báo cáo khối lượng đã thực hiện và đối chiếu với kế hoạch tiến độ, định mức. Việc theo dõi sâu sát, thường xuyên như vậy giúp quản lý được các chi phí phát sinh thuộc phạm vi trách nhiệm để kịp thời phát hiện các hạn chế, sai sót phát sinh ngoài dự toán; phòng ngừa được việc thực hiện không đúng kế hoạch. Khi công việc đã hoàn thành, trưởng các bộ phận tổng hợp toàn bộ các chi phí thực tế phát sinh và gửi báo cáo về cho trung tâm chi phí. Trung tâm chi phí sẽ sử dụng các báo cáo này để lập báo cáo tình hình thực hiện chi phí. Báo cáo này là căn cứ quan trọng để đánh giá thành quả của trung tâm chi phí.

\section{b. Trung tâm doanh thu}

Trung tâm doanh thu gắn với trách nhiệm của cửa hàng trưởng, trưởng bộ phận bán hàng hoặc trưởng phòng kinh doanh. Mục tiêu của trung tâm doanh thu là tối đa hóa doanh thu trên thị trường. Từ đó để đánh giá được trung tâm này chúng ta cần đánh giá những nội dung sau:

- Giá và khối lượng bán ra so với kế hoạch;

- Sự thay đổi về giá và khối lượng sản phẩm theo thị hiếu, theo mùa, xu hướng thời trang... Nội dung này phản ánh mức độ phản ứng của trung tâm trên thị trường;

- Doanh thu của từng mặt hàng, doanh thu theo thị trường, doanh thu theo cửa hàng, doanh thu theo thời gian... Nội dung này sẽ xác định kết quả và hiệu quả của mạng lưới kinh doanh.

Ngoài ra có thể yêu cầu trung tâm báo cáo kết quả đại diện bán hàng, qua đó xem xét kết quả của từng người bán cũng như chênh lệch giữa thực tế đạt được so với dự toán đã được duyệt. Từ đó, nhà quản trị có thể đánh giá hiệu quả của từng người bán, đồng thời phân tích được các nguyên nhân, xác định được các biện pháp điều chỉnh.

\section{c. Trung tâm lợi nhuận}

Trách nhiệm của nhà quản trị ở trung tâm lợi nhuận là tổ chức hoạt động kinh doanh sao cho lợi nhuận đạt được là cao nhất. Do lợi nhuận bằng doanh thu trừ chi phí nên để đánh giá kết quả của trung tâm lợi nhuận, chúng ta cần đánh giá việc thực hiện các chỉ tiêu lợi nhuận, giá bán và lượng bán. Chỉ tiêu đánh giá kết quả ở trung tâm lợi nhuận có thể là: lợi nhuận đạt được trong kỳ, lợi nhuận tính trên đơn vị sản phẩm,... Ở khía cạnh hiệu quả, do có thể lượng hóa được bằng tiền ở cả đầu ra và đầu vào, nên hiệu quả hoạt động của trung tâm lợi nhuận có thể đo lường bằng các chỉ tiêu: Tỷ suất lợi nhuận trên doanh thu; tỷ suất doanh thu trên chi phí...

\section{d. Trung tâm đầu tư}

Để đánh giá trách nhiệm của trung tâm đầu tư, nhà quản trị sử dụng chỉ tiêu ROI và RI. Thông qua chỉ tiêu ROI, ta sẽ thấy được hiệu quả sử dụng vốn của trung tâm gắn với trách nhiệm của nhà quản trị. Chỉ tiêu RI là một chỉ tiêu tuyệt đối, không giống như ROI là một chỉ tiêu tương đối. RI thực chất là lợi nhuận còn lại của một trung tâm đầu tư sau khi loại trừ chi phí sử dụng vốn đầu tư. Tuy nhiên, 
chỉ tiêu ROI và RI đều có những hạn chế nhất định trong việc đánh giá hiệu quả hoạt động của trung tâm, do đó, doanh nghiệp nên sử dụng phối hợp cả hai chỉ tiêu đánh giá này. Ngoài ra còn những tiêu chuẩn đánh giá khác như: mức tăng trưởng doanh thu, thị phần...

\section{Kết luận}

Hệ thống kế toán trách nhiệm bao gồm các công cụ, chỉ tiêu đánh giá hướng các nhà quản lý bộ phận đến thực hiện các mục tiêu chung của tổ chức. Các doanh nghiệp nhỏ và vừa nếu có sự phân cấp rõ ràng và biết cách vận dụng kế toán trách nhiệm vào quá trình thực tế chắc chắn sẽ giúp cho doanh nghiệp đó kiểm soát, quản lý một cách hiệu quả. Việc quy trách nhiệm cụ thể sẽ giúp nâng cao tinh thần trách nhiệm của từng bộ phận, từng nhà quản trị của các trung tâm trách nhiệm, qua đó, góp phần nâng cao hiệu quả hoạt động kinh doanh của doanh nghiệp nhỏ và vừa một cách bền vững.

\section{TÀI LIỆU THAM KHẢO}

1. Hồ Mỹ Hạnh, Kế toán trách nhiệm và mối quan hệ với cấu trúc tổ chức của doanh nghiệp, http://tapchitaichinh.vn/nghien-cuu--trao-doi/trao-doi-binh-luan/ke-toan-trach-nhiem-va-moiquan-he-voi-cau-truc-to-chuc-cua-doanh-nghiep-58306.html, 04/2/2015;

2. Đàm Phương Lan (2014), Kế toán trách nhiệm và ưng dụng kế toán trách nhiệm tại công ty cổ phần đầu tu và thuoong mại Thái Nguyên - TNG, Tạp chí Khoa học \& Công nghệ, Số 117;

3. Nguyễn Ngọc Quang (2015), Giáo trình Kế toán quản trị, Nxb Đại học Kinh tế quốc dân, Hà Nội;

4. Phùng Lệ Thủy, Nâng cao hiệu quả quản lý doanh nghiệp bằng kế toán trách nhiệm, http://www.khoahockiemtoan.vn/Category.aspx? newsID=585\&AspxAutoDetectCookieSupport= $1,07 / 4 / 2014$. 